\title{
Risk for Fracture in Women with Low Serum Levels of Thyroid-Stimulating Hormone
}

Douglas C. Bauer, MD; Bruce Ettinger, MD; Michael C. Nevitt, PhD; and Katie L. Stone, PhD, for the Study of Osteoporotic Fractures Research Group

Background: Biochemical evidence of hyperthyroidism may be associated with low bone mass, particularly in older postmenopausal women, but no prospective studies of thyroid function and subsequent fracture risk have been done.

Objective: To examine the association between low levels of thyroid-stimulating hormone (TSH) and fracture in older women.

Design: Prospective cohort study with case-cohort sampling.

Setting: Four clinical centers in the United States.

Patients: 686 women older than 65 years of age from a cohort of 9704 women recruited from population-based listings between 1986 and 1988.

Measurements: Baseline assessment of calcaneal bone mass, spine radiography, and history of thyroid disease. Spine radiography was repeated after a mean follow-up of 3.7 years; nonspine fractures were centrally adjudicated. Thyroid-stimulating hormone was measured in sera obtained at baseline from 148 women with new hip fractures, 149 women with new vertebral fractures, and a subsample of 398 women randomly selected from the cohort.
Results: After adjustment for age, history of previous hyperthyroidism, self-rated health, and use of estrogen and thyroid hormone, women with a low TSH level ( $\leq 0.1 \mathrm{mU} / \mathrm{L}$ ) had a threefold increased risk for hip fracture (relative hazard, $3.6[95 \% \mathrm{Cl}, 1.0$ to 12.9]) and a fourfold increased risk for vertebral fracture (odds ratio, $4.5[\mathrm{Cl}, 1.3$ to 15.6$])$ compared with women who had normal TSH levels ( 0.5 to $5.5 \mathrm{mU} / \mathrm{L}$ ). After adjustment for TSH level, a history of hyperthyroidism was associated with a twofold increase in hip fracture (relative hazard, $2.2[\mathrm{Cl}, 1.0$ to 4.4$]$ ), but use of thyroid hormone itself was not associated with increased risk for hip fracture (relative hazard, $0.5[\mathrm{Cl}, 0.2$ to 1.3$]$ ).

Conclusions: Women older than 65 years of age who have low serum TSH levels, indicating physiologic hyperthyroidism, are at increased risk for new hip and vertebral fractures. Use of thyroid hormone itself does not increase risk for fracture if TSH levels are normal.

Ann Intern Med. 2001;134:561-568.

www.annals.org

For author affiliations, current addresses, and contributions, see end of text.
O steoporosis and thyroid dysfunction are both common in older women; $8 \%$ to $13 \%$ of women older than 50 years of age have biochemical evidence of thyroid dysfunction $(1,2)$, and $30 \%$ are osteoporotic according to bone density criteria (3). Although osteoporotic fractures have long been associated with florid hyperthyroidism (4) and, more recently, with a history of hyperthyroidism in older women (5), the relationship between biochemical evidence of excess thyroid hormone and fracture risk is not known $(6,7)$.

Indirect evidence suggests that excess thyroid hormone due to endogenous disease or exogenous overuse of thyroid hormone may be associated with detrimental effects on bone, even in asymptomatic persons. For example, several biochemical markers of bone turnover are elevated in women with excess thyroid hormone $(8,9)$. Findings from studies of the relationship between excess thyroid hormone and bone mass are conflicting (1017). However, factors other than bone mass, such as neuromuscular function and bone quality, contribute to risk for fracture (5) and may be adversely affected by excess thyroid hormone. Results of previous small, retrospective studies of thyroid function and fractures have also been conflicting (18-21). To our knowledge, no large prospective studies have examined the relationship between excess thyroid hormone and subsequent fracture.

In light of the conflicting information on bone mass and the paucity of studies with fracture as an end point, several experts have noted the need for longitudinal studies of thyroid function and fracture risk (22-26). To test the hypothesis that low levels of serum thyroidstimulating hormone (TSH) increase the risk for hip, vertebral, and any nonspine fracture, we performed a prospective study of postmenopausal women enrolled in the Study of Osteoporotic Fractures.

\section{Methods}

Patients

The Study of Osteoporotic Fractures is a prospective cohort study of risk factors for fracture among 9704 
ARTICLE $\mid$ Low Serum Levels of Thyroid-Stimulating Hormone and Risk for Fracture

women (5). White women older than 65 years of age were recruited in 1986 to 1988 from population-based listings at four clinical centers (Portland, Oregon; Minneapolis, Minnesota; Pittsburgh, Pennsylvania; and Baltimore, Maryland). The institutional review boards of all four centers gave approval for this study involving human research subjects.

\section{Measurements}

\section{Baseline Measurements}

Participants were interviewed and examined during the baseline visit. Detailed information about physiciandiagnosed medical conditions and past medication use was collected, and trained interviewers confirmed current medication use by examination of pill bottles. Participants were asked specifically about self-rated health, previous physician diagnoses of hyperthyroidism or Graves disease, and previous use of thyroid hormone. In addition to standardized assessments of height and weight, bone mass of the calcaneus was determined by using single-photon absorptiometry (OsteoAnalyzer, Siemens-Osteon, Wahiawa, Hawaii) and lateral radiographs of the thoracic and lumbar spine were obtained $(27,28)$. Serum was collected from each participant and stored at $-190^{\circ} \mathrm{C}$. Approximately 2 years after the baseline visit, bone mineral density of the proximal femur was measured in $82 \%$ of the cohort by using dualenergy x-ray absorbtiometry (Hologic QDR 1000, Waltham, Massachusetts) (29).

Levels of TSH were measured in archived sera obtained at baseline by using a highly sensitive, third-generation chemiluminescent assay (Endocrine Science, Calabasas, California). The normal range for this assay is 0.5 to $5.5 \mathrm{mU} / \mathrm{L}$; the functional sensitivity (defined as the concentration at which the interassay coefficient of variation is $\geq 20 \%$ ) is approximately $0.05 \mathrm{mIU} / \mathrm{L}$ (30). At TSH concentrations of $0.5 \mathrm{mIU} / \mathrm{L}$, the intra-assay coefficient of variation is $4.7 \%$ and the interassay coefficient of variation is $6.3 \%$. Thirty randomly selected specimens were blindly submitted for duplicate analysis; the correlation between these two TSH results was high $(r=0.95)$. Previous studies have shown that TSH levels are highly stable in frozen sera over prolonged periods $(31,32)$. Other studies have demonstrated that among ambulatory adults, TSH levels of $0.1 \mathrm{mIU} / \mathrm{L}$ or less are highly correlated with a diminished response to thyroid- releasing hormone stimulation (33) and are associated with an increased incidence of atrial fibrillation (34).

\section{Ascertainment of Incident Fractures}

After the baseline visit, women were contacted by mail every 4 months about the occurrence of fractures. Hip fractures were confirmed by review of the appropriate radiographs by a radiologist at the coordinating center; other nonspine fractures were confirmed by review of written radiology reports. Fractures resulting from excessive trauma (such as motor vehicle accidents) were excluded. Follow-up for fracture and vital status was more than $99 \%$ complete.

Lateral spine radiographs were repeated in 7299 women $(79 \%$ of surviving women) after a mean $( \pm S D)$ follow-up of $3.7 \pm 0.4$ years, and 7238 pairs of radiographs were judged to be adequate for assessment of incident vertebral fractures. Women without follow-up radiographs were older and reported poorer health at baseline compared with those who had follow-up radiographs (35). Vertebral fractures were identified by using computer-assisted morphometric evaluation (36), and incident vertebral fractures were defined as a $20 \%$ or greater and $4 \mathrm{~mm}$ or greater reduction in anterior, midvertebral, or posterior vertebral height between the baseline and follow-up radiographs (37). The persons who assessed the radiographs had no knowledge of the participant's medical history or TSH level.

\section{Selection of Case and Control Samples for Fracture Analyses}

Using an efficient case-cohort approach that maintains statistical power but avoids expensive biochemical measurements in the entire cohort $(38-40)$, we randomly selected baseline serum samples from 148 women with hip fracture and 149 women with incident vertebral fracture after the baseline visit. We randomly selected 398 women from the original cohort, independent of fracture status, to be controls. This random sample, which we refer to as "the subsample" in this report, included 14 of the 148 women selected as incident hip fracture cases and 15 of the 149 women selected as incident vertebral fracture cases; these women were removed from the subsample and were analyzed as cases of hip and vertebral fracture, respectively. To create a fracture-free control group, we excluded women 
from the subsample with other nonspine fractures during follow-up ( $n=80$ for the hip fracture analyses and $n=58$ for the vertebral fracture analyses). Ninety women in the subsample had missing or technically inadequate radiographs and could not be analyzed for vertebral fracture outcomes.

The analyses of any nonspine fracture were performed in the randomly selected subsample by using standard prospective cohort methods. After 14 women with unconfirmed fracture, 5 women with fracture from extreme trauma, and 6 women with spine fractures were excluded, the analysis of nonspine fracture included 100 women with documented nonspine fracture occurring after study entry and 273 without fracture. Random selection was done by using a computerized randomnumber generator.

\section{Statistical Analysis}

Continuous variables were plotted, and distributions, means, and standard deviations were examined. Levels of TSH were categorized as low $(\leq 0.1 \mathrm{mIU} / \mathrm{L})$, borderline low $(>0.1$ but $<0.5 \mathrm{mIU} / \mathrm{L})$, normal $(0.5$ to $5.5 \mathrm{mIU} / \mathrm{L})$, or high $(>5.5 \mathrm{mIU} / \mathrm{L})$.

Associations with hip fracture were examined by using proportional hazards analyses (Epicure, Hirosoft International, Seattle, Washington) that took into account the case-cohort sampling design. The proportionality assumption was not violated. Results are reported as relative hazards with 95\% CIs. Logistic regression was used to analyze incident vertebral fracture; these results are reported as odds ratios with 95\% CIs. Cox proportional hazards models were used to determine associations with nonspine fracture among the randomly selected subsample.

Multivariate models were constructed to adjust for potential confounders. Potential confounders were selected on the basis of biologic plausibility (for example, use of thyroid hormone) or a strong univariate association $(P \leq 0.1)$ with TSH level (for example, age) or fracture (for example, estrogen use). We found no association $(P>0.1)$ between TSH level and maternal history of fracture, height, neuromuscular function, or corticosteroid use, which are known to be associated with fracture in this cohort (5). The final multivariate models for each fracture type included TSH level, age, previous hyperthyroidism, self-rated health, and current use of thyroid hormone and estrogen.
To determine whether the increased risk for fracture in women with low TSH levels was mediated by reduced bone mass or some other mechanism, we examined the effect of further adjusting the final multivariate models for calcaneal bone mass measured at the baseline visit. The effect of adjustment for bone mineral density at the femoral neck, measured approximately 2 years after the baseline visit, was similar to that observed for calcaneal bone mineral density.

\section{Role of the Funding Source}

The funding source had no role in the collection, analysis, interpretation, or publication of these data.

\section{RESULTS}

During a maximum follow-up of 5.9 years, 332 women had a first hip fracture, 389 had an incident vertebral fracture detected on paired spinal radiographs, and 2520 had nonspine fractures. Women who had incident hip, vertebral, or any nonspine fractures were older and had lower bone mass than controls (Table 1). Women with hip fractures were more likely to report previous hyperthyroidism. Mean TSH levels were similar among women with and without fracture, but the proportion of women with a low TSH level $(\leq 0.1$ $\mathrm{mIU} / \mathrm{L}$ ) was significantly greater among those with hip or vertebral fracture. Overall, $11 \%$ of participants reported thyroid hormone use at the baseline visit, whereas $86 \%$ of women with low TSH levels reported thyroid hormone use. Among the 42 women with TSH levels of $0.1 \mathrm{mIU} / \mathrm{L}$ or less, $29(69 \%)$ had levels of 0.05 $\mathrm{mIU} / \mathrm{L}$ or less.

\section{TSH Level and Hip Fracture}

The risk for hip fracture during follow-up was more than threefold higher among women with low TSH levels than those with normal TSH levels (Table 2). Adjustment for age, previous hyperthyroidism, self-rated health, and current use of estrogen and thyroid hormone had little effect. Additional adjustment for body weight, which was lower in women with hip fracture and is likely to be mediated by excess thyroid hormone, had minimal effect on the relationship between low TSH level and hip fracture (relative hazard, 3.2 [95\% CI, 0.9 to 11.6]). After further adjustment for calcaneal bone mineral density, the risk for new hip fracture was still elevated among women with low TSH levels, but the

$$
3 \text { April } 2001 \mid \text { Annals of Internal Medicine } \mid \text { Volume } 134 \cdot \text { Number } 7 \mid \mathbf{5 6 3}
$$


ARTICLE $\mid$ Low Serum Levels of Thyroid-Stimulating Hormone and Risk for Fracture

Table 1. Baseline Characteristics of Women with and without Incident Hip, Vertebral, or Any Nonspine Fracture*

\begin{tabular}{|c|c|c|c|c|c|c|}
\hline & \multicolumn{2}{|c|}{ Hip } & \multicolumn{2}{|c|}{ Vertebral } & \multicolumn{2}{|c|}{ Any Nonspine } \\
\hline & $\begin{array}{l}\text { Fracture } \\
(n=148)\end{array}$ & $\begin{array}{l}\text { No Fracture } \\
(n=304)\end{array}$ & $\begin{array}{l}\text { Fracture } \\
(n=149)\end{array}$ & $\begin{array}{l}\text { No Fracture } \\
(n=235) \dagger\end{array}$ & $\begin{array}{l}\text { Fracture } \\
(n=100)\end{array}$ & $\begin{array}{l}\text { No Fracture } \\
(n=273)\end{array}$ \\
\hline Body weight, $\mathrm{kg}$ & $62.1 \pm 13.4 \ddagger$ & $67.6 \pm 12.6$ & $63.7 \pm 11.5 \ddagger$ & $68.2 \pm 12.6$ & $66.6 \pm 13.1$ & $67.5 \pm 12.0$ \\
\hline History of hyperthyroidism, \% & $16.1 \S$ & 8.2 & 10.3 & 8.7 & 10.4 & 8.8 \\
\hline Good or excellent self-rated health, $\%$ & $75.0 \S$ & 84.5 & $81.9 \S$ & 89.4 & 77.0 & 83.4 \\
\hline Calcaneal BMD, $\mathrm{g} / \mathrm{cm}^{2}$ & $0.35 \pm 0.10 \neq$ & $0.42 \pm 0.09$ & $0.35 \pm 0.08 \ddagger$ & $0.42 \pm 0.08$ & $0.38 \pm 0.11 \neq$ & $0.42 \pm 0.08$ \\
\hline Femoral neck $\mathrm{BMD}, \mathrm{g} / \mathrm{cm}^{2}$ & $0.55 \pm 0.09 \ddagger$ & $0.66 \pm 0.10$ & $0.58 \pm 0.09 \ddagger$ & $0.67 \pm 0.10$ & $0.64 \pm 0.12 \S$ & $0.67 \pm 0.10$ \\
\hline TSH level, $m / U / L$ & $2.0 \pm 2.5$ & $2.3 \pm 3.3$ & $2.5 \pm 6.3$ & $2.5 \pm 3.7$ & $2.1 \pm 2.8$ & $2.4 \pm 3.5$ \\
\hline Low TSH level ( $\leq 0.1 \mathrm{mlU} / \mathrm{L}), \%$ & $9.5 \ddagger$ & 2.6 & $9.4 \S$ & 3.4 & 6.0 & 2.6 \\
\hline High TSH level (>5.5 mlU/L), \% & 6.8 & 6.6 & 4.7 & 8.5 & 8.0 & 7.0 \\
\hline
\end{tabular}

* Data with the plus/minus sign are the mean \pm SD. BMD = bone mineral density; TSH $=$ thyroid-stimulating hormone.

t The number of controls for the vertebral fracture analysis is smaller because women without technically adequate films obtained at baseline and follow-up films were excluded.

$\ddagger P<0.01$ compared with respective controls.

$\S P<0.05$ compared with respective controls.

relationship was no longer statistically significant (relative hazard ratio, 2.3 [CI, 0.6 to 8.5$]$ ).

Relative to women with normal TSH levels, the risk for hip fracture was not significantly increased among women with borderline low TSH levels $(0.1$ to 0.5 $\mathrm{mIU} / \mathrm{L})$ (Table 2).

\section{TSH Level and Vertebral Fracture}

The risk for new (incident) vertebral fracture during follow-up was threefold higher among women with low TSH levels than those with normal TSH levels (Table 3). After adjustment for age, previous hyperthyroidism, self-rated health status, and current use of estrogen and thyroid hormone, the risk for new vertebral fracture was more than fourfold greater in women with low TSH levels. Additional adjustment for body weight, which

\section{Table 2. Thyroid Disease and Risk for Hip Fracture}

\begin{tabular}{|lll}
\hline \multirow{2}{*}{ Factor } & \multicolumn{2}{l}{ Relative Hazard Ratio $(95 \% \mathrm{Cl})$} \\
\cline { 2 - 3 } & & \\
\cline { 2 - 3 } & Unadjusted & Adjusted* \\
Thyroid-stimulating hormone level & & \\
$\quad$ Normal $(0.5-5.5 \mathrm{mIU} / \mathrm{L})$ & 1.0 (referent) & 1.0 (referent) \\
$\quad$ Borderline low $(>0.1-<0.5 \mathrm{mIU} / \mathrm{L})$ & $1.7(0.9-3.6)$ & $1.9(0.7-4.8)$ \\
$\quad$ Low $(\leq 0.1 \mathrm{mIU} / \mathrm{L})$ & $3.4(1.5-7.9)$ & $3.6(1.0-12.9)$ \\
$\begin{array}{l}\text { Use of thyroid hormone } \\
\text { Previous hyperthyroidism }\end{array}$ & $1.3(0.7-2.3)$ & $0.5(0.2-1.3)$ \\
Age (per 5-year increase) & $2.1(1.2-3.8)$ & $2.2(1.0-4.4)$ \\
Good or excellent self-rated health & $1.7(1.5-2.1)$ & $1.6(1.4-2.0)$ \\
$\quad$ (vs. fair or poor) & $0.5(0.3-0.8)$ & $0.6(0.3-1.0)$ \\
Current oral estrogen use & $1.1(0.6-2.1)$ & $1.3(0.7-2.8)$ \\
\end{tabular}

* Adjusted for all other variables in table. was lower in women with incident vertebral fractures, slightly reduced the strength of the association between low TSH level and fracture (odds ratio, 4.1 [CI, 1.2 to 14.3]). After further adjustment for calcaneal bone mineral density, the risk for new vertebral fracture was still elevated among women with low TSH levels, but the relationship was no longer statistically significant (odds ratio, 3.1 [CI, 0.9 to 11.2 ]).

After adjustment for potential confounders, the risk for vertebral fracture was nearly threefold greater among women with borderline low TSH levels than among those with normal TSH levels (Table 3).

\section{TSH Level and Nonspine Fracture}

Compared with women who had normal TSH levels, women with low TSH levels at the baseline visit had a twofold greater risk for any nonspine fracture during follow-up (Table 4). After adjustment for potential confounders, the magnitude of this association was unchanged, but it was no longer statistically significant (relative hazard ratio, 2.2 [CI, 0.8 to 6.6]).

\section{Previous Hyperthyroidism, Thyroid Hormone Use, and Fracture Risk}

The risk for hip fracture was twofold higher among women with a history of hyperthyroidism (Table 2). This risk persisted after adjustment for TSH level and other potential confounders (relative hazard, $2.2[\mathrm{CI}$, 1.0 to 4.4]). Further adjustment for baseline calcaneal 
bone mineral density did not alter the relationship between previous hyperthyroidism and hip fracture (relative hazard, 2.5 [CI, 1.1 to 5.4]). Previous hyperthyroidism was not associated with increased risk for vertebral fracture (Table 3) or nonspine fracture (Table 4).

Thyroid hormone use was not associated with increased risk for hip, vertebral, or any nonspine fracture in unadjusted analyses, and results were similar after adjustment for TSH level, age, previous hyperthyroidism, self-rated health, and current estrogen use (Tables 2, 3, and 4).

\section{Discussion}

In this large prospective study of thyroid function and subsequent fracture among women older than 65 years of age, those with TSH levels of $0.1 \mathrm{mIU} / \mathrm{L}$ or less had a significantly increased risk for new hip and vertebral fractures. This adverse effect was independent of age, previous hyperthyroidism, self-rated health, and use of estrogen and thyroid hormone. The risk for vertebral fracture, but not hip or other nonspine fracture, was significantly elevated among women with borderline low TSH levels ( 0.1 to $0.5 \mathrm{mIU} / \mathrm{L})$. Women who reported previous hyperthyroidism had an increased risk for hip fracture, but we found no evidence that thyroid hormone use itself was associated with an increased risk of fracture.

The relationship between excess thyroid hormone and osteoporosis has been controversial. Although overt hyperthyroidism is associated with osteoporosis (4143), previous studies have produced conflicting data on the effect of excess thyroid hormone and bone mass (10, $11,15,16)$ or bone loss $(31,44)$. Biochemical markers

Table 3. Thyroid Disease and Risk for Vertebral Fracture

\begin{tabular}{|c|c|c|}
\hline \multirow[t]{2}{*}{ Factor } & \multicolumn{2}{|c|}{ Odds Ratio $(95 \% \mathrm{Cl})$} \\
\hline & Unadjusted & Adjusted* \\
\hline \multicolumn{3}{|l|}{ Thyroid-stimulating hormone level } \\
\hline Normal $(0.5-5.5 \mathrm{mIU} / \mathrm{L})$ & 1.0 (referent) & 1.0 (referent) \\
\hline Borderline low $(>0.1-<0.5 \mathrm{mIU} / \mathrm{L})$ & $1.9(0.7-4.5)$ & $2.8(1.0-8.5)$ \\
\hline Low ( $\leq 0.1 \mathrm{mIU} / \mathrm{L})$ & $2.9(1.2-7.2)$ & $4.5(1.3-15.6)$ \\
\hline Current use of thyroid hormone & $1.2(0.6-2.3)$ & $0.4(0.2-1.3)$ \\
\hline Previous hyperthyroidism & $1.2(0.6-2.4)$ & $1.3(0.6-2.9)$ \\
\hline Age (per 5-year increase) & $1.4(1.1-1.7)$ & $1.3(1.1-1.6)$ \\
\hline $\begin{array}{l}\text { Good or excellent self-rated health } \\
\text { (vs. fair or poor) }\end{array}$ & $0.5(0.3-1.0)$ & $0.6(0.3-1.0)$ \\
\hline Current oral estrogen use & $0.8(0.4-1.6)$ & $0.8(0.4-1.8)$ \\
\hline
\end{tabular}

* Adjusted for all other variables in table.
Table 4. Thyroid Disease and Risk for Nonspine Fracture

\begin{tabular}{|c|c|c|}
\hline \multirow[t]{2}{*}{ Factor } & \multicolumn{2}{|c|}{ Relative Hazard Ratio $(95 \% \mathrm{Cl})$} \\
\hline & Unadjusted & Adjusted* \\
\hline \multicolumn{3}{|l|}{ Thyroid-stimulating hormone level } \\
\hline Normal $(0.5-5.5 \mathrm{mlU} / \mathrm{L})$ & 1.0 (referent) & 1.0 (referent) \\
\hline Borderline low $(>0.1-<0.5 \mathrm{mlU} / \mathrm{L})$ & $1.6(0.8-3.3)$ & $2.0(0.9-4.5)$ \\
\hline Low $(\leq 0.1 \mathrm{mlU} / \mathrm{L})$ & $2.2(1.0-5.0)$ & $2.3(0.8-6.8)$ \\
\hline Use of thyroid hormone & $1.2(0.6-2.1)$ & $0.7(0.3-1.7)$ \\
\hline Previous hyperthyroidism & $1.2(0.6-2.4)$ & $0.9(0.4-2.0)$ \\
\hline Age (per 5-year increase) & $1.2(1.0-1.5)$ & $1.2(1.0-1.5)$ \\
\hline $\begin{array}{l}\text { Good or excellent self-rated health } \\
\text { (vs. fair or poor) }\end{array}$ & $0.6(0.4-1.0)$ & $0.6(0.4-0.9)$ \\
\hline Current oral estrogen use & $0.8(0.4-1.6)$ & $0.8(0.4-1.7)$ \\
\hline
\end{tabular}

* Adjusted for all other variables in table.

of bone turnover, such as serum osteocalcin and urine $N$-teleopeptide of type 1 collagen, are elevated in persons with evidence of excess thyroid hormone $(8,9,45)$. Some studies have found that elevated levels of biochemical markers of bone turnover are associated with increased risk for fracture independent of bone mineral density $(46,47)$.

Relatively few studies have examined the relation between excess thyroid hormone and fractures. An older study (18) found no significant overall increase in the rate of fracture among 306 women with treated hyperthyroidism compared with age-matched controls. A more recent study (20) found that thyroid hormone users with low TSH levels $(<0.05 \mathrm{mIU} / \mathrm{L})$ did not have an increased rate of hospitalization for fracture compared with persons who had normal TSH levels. Of note, in that study, the risk for hospitalization because of fracture was approximately twofold greater in persons older than 65 years of age with low TSH levels. Another retrospective study (19) found that women with a history of hyperthyroidism or thyroid cancer appeared to have their first fracture earlier than women without thyroid disease, and two recent case-control studies of endogenous hyperthyroidism and fracture had conflicting results $(21,48)$.

We previously reported that a history of hyperthyroidism was associated with increased risk for hip fracture in the full Study of Osteoporotic Fractures cohort (5). The current study confirms the adverse skeletal consequences of previous hyperthyroidism and extends our previous findings in that the relationship between previous hyperthyroidism and hip fracture seems to be independent of TSH level and calcaneal bone mineral

3 April $2001 \mid$ Annals of Internal Medicine $\mid$ Volume $134 \bullet$ Number $7 \mid 565$ 
ARTICLE $\mid$ Low Serum Levels of Thyroid-Stimulating Hormone and Risk for Fracture

density. These data raise the possibility that the longterm adverse skeletal effects of endogenous hyperthyroidism (or its treatment) are not mediated by persistent hyperthyroidism or reduced bone mass. Conversely, adjustment for baseline calcaneal bone density attenuated the relationship between low TSH level and fracture, suggesting that low TSH may increase fracture risk in part by reducing bone mass. Further studies are necessary to determine whether other mechanisms, such as poor bone quality from accelerated remodeling, explain these observations.

Compared with previous studies, our prospective study had several important strengths: It was larger, used population-based sampling, carefully documented potential confounders (such as estrogen use and previous hyperthyroidism), followed participants over an extended period, and adjudicated fractures by using objective and validated methods. Biochemical markers of bone turnover were elevated in women with low TSH levels in this sample (44), supporting the view that low TSH levels reflect excessive thyroid hormone, which in turn increases skeletal remodeling (49).

Our study also had limitations. Because of insufficient sera, we could not measure thyroxine or triidothyronine levels in women with low TSH levels, and we therefore could not determine the independent effect of thyroid hormone levels on risk for fracture. Other studies have demonstrated that most persons with low but detectable TSH levels while taking exogenous thyroid have normal thyroid hormone levels, and nearly half of those with TSH levels of $0.05 \mathrm{mIU} / \mathrm{L}$ or less have normal thyroid hormone levels (50). In our study, 69\% of women with low TSH levels had levels less than 0.05 $\mathrm{mIU} / \mathrm{L}$, and too few fractures occurred to allow separate analysis of women with TSH levels between 0.05 and $0.1 \mathrm{mIU} / \mathrm{L}$. Further study of risk for fracture among women with low TSH levels but normal thyroid hormone levels is needed. Levels of TSH were measured only once, and some women may have had transiently low levels; however, a second TSH measurement would probably only have strengthened the observed association between low TSH and fracture. In addition, we cannot rule out the possibility that a small number of women in our cohort had low TSH levels as a result of severe medical or psychiatric illness (51), but the adverse effects of low TSH persisted after adjustment for selfrated health. Thyroid-stimulating hormone was mea- sured in sera that had been archived for approximately 6 to 8 years at $-190{ }^{\circ} \mathrm{C}$; although the effects of long-term storage at these temperatures have not been studied, the TSH levels reported in this study were similar to those in other similar older cohorts (52). Finally, most of the study participants were older women, and $86 \%$ of those with low TSH levels were taking thyroid hormone; generalization of these results to other populations must be done with caution.

Because this was an observational study, we could not rule out the possibility that low TSH levels might have been a physiologic marker for increased fracture risk for reasons other than physiologic hyperthyroidism. A randomized clinical trial in which TSH were normalized in one group and not in another group would be necessary. Likewise, our study provides no direct information on whether normalization of TSH level would reduce risk for fracture among women with low bone mineral density who are taking thyroid hormone replacement. However, if physiologic hyperthyroidism contributes to increased skeletal fragility and increased risk for fracture, a lower dose of hormone might be beneficial. Finally, our study does not indicate whether normalization of TSH level is more or less effective than therapies aimed at reducing the risk for fracture by increasing bone mineral density or preventing bone loss. However, since decreasing the dose of thyroid hormone to normalize the TSH level has no known adverse effects, our findings suggest that a prudent clinical course of action may be to maintain TSH levels in the normal range. Furthermore, use of suppressive thyroid hormone therapy for benign conditions should be reconsidered in light of the adverse skeletal consequences of low TSH level. Our findings suggest that thyroid hormone use itself is not associated with an increased risk for fracture. Although the majority of women with low TSH levels in this study were taking thyroid hormone, those with normal TSH levels while taking thyroid hormone did not have an increased risk for fracture.

In conclusion, we found that older women with biochemical evidence of excess thyroid hormone have an increased risk for hip and vertebral fractures. We found no evidence that thyroid hormone use itself adversely effects fracture rates if TSH levels are normal, but previous hyperthyroidism is independently associated with an increased risk for hip fracture, even after adjustment for TSH levels and bone mineral density. Additional 
Low Serum Levels of Thyroid-Stimulating Hormone and Risk for Fracture $\mid$ ARTICLE

studies are needed to determine whether these findings apply equally to women not taking thyroid hormone or whether the increased risk for fracture is limited to those with elevated levels of thyroid hormone.

From University of California, San Francisco, San Francisco, California; University of Pittsburgh, Pittsburgh, Pennsylvania; University of Minnesota, Minneapolis, Minnesota; and Kaiser Permanente Medical Care Program, Oakland, California.

Grant Support: By Public Service Grant K08 AG00629 from the National Institute on Aging.

Requests for Single Reprints: Douglas C. Bauer, MD, University of California, San Francisco, 74 New Montgomery, Suite 600, San Francisco, CA 94105.

Current Author Addresses: Drs. Bauer, Nevitt, and Stone: University of California, San Francisco, 74 New Montgomery, Suite 600, San Francisco, CA 94105.

Dr. Ettinger: Division of Research, Kaiser Permanente, 3505 Broadway, 7th Floor, Oakland, CA 94611.

Author Contributions: Conception and design: D.C. Bauer. Analysis and interpretation of the data: D.C. Bauer, B. Ettinger, M.C. Nevitt, K.L. Stone.

Drafting of the article: D.C. Bauer.

Critical revision of the article for important intellectual content: D.C. Bauer, B. Ettinger, M.C. Nevitt, K.L. Stone.

Final approval of the article: D.C. Bauer, B. Ettinger, M.C. Nevitt, K.L. Stone.

Statistical expertise: M.C. Nevitt, K.L. Stone.

Obtaining of funding: D.C. Bauer.

Administrative, technical, or logistic support: K.L. Stone.

\section{References}

1. Sawin CT, Geller A, Hershman JM, Castelli W, Bacharach P. The aging thyroid. The use of thyroid hormone in older persons. JAMA. 1989;261:2653-5. [PMID: 0002709545]

2. Grund FM, Niewoehner CB. Hyperthyroxinemia in patients receiving thyroid replacement therapy. Arch Intern Med. 1989;149:921-4. [PMID: 0002705841]

3. Melton LJ 3rd, Chrischilles EA, Cooper C, Lane AW, Riggs BL. Perspective. How many women have osteoporosis? J Bone Miner Res. 1992;7:1005-10. [PMID: 0001414493]

4. Von Recklinghausen F. Festschrift Rudolf Virchow. Berlin: Reimer; 1891. (Reimer G, ed. Die Fibrose oder deformirende Ostitis die Osteomalacie und die osteoplastische Carcinose).

5. Cummings SR, Nevitt MC, Browner WS, Stone K, Fox KM, Ensrud KE, et al. Risk factors for hip fracture in white women. Study of Osteoporotic Fractures Research Group. N Engl J Med. 1995;332:767-73. [PMID: 0007862179]

6. Auwerx J, Bouillon R. Mineral and bone metabolism in thyroid disease: a review. Q J Med. 1986;60:737-52. [PMID: 0003774957]

7. Helfand M, Redfern CC. Clinical guideline, part 2. Screening for thyroid disease: an update. American College of Physicians. Ann Intern Med. 1998;129:
144-58. [PMID: 0009669977]

8. Krakauer JC, Kleerekoper M. Borderline-low serum thyrotropin level is correlated with increased fasting urinary hydroxyproline excretion. Arch Intern Med. 1992;152:360-4. [PMID: 0001739367]

9. Harvey RD, McHardy KC, Reid IW, Paterson F, Bewsher PD, Duncan A, et al. Measurement of bone collagen degradation in hyperthyroidism and during thyroxine replacement therapy using pyridinium cross-links as specific urinary markers. J Clin Endocrinol Metab. 1991;72:1189-94. [PMID: 0002026741]

10. Ross DS, Neer RM, Ridgway EC, Daniels GH. Subclinical hyperthyroidism and reduced bone density as a possible result of prolonged suppression of the pituitary-thyroid axis with L-thyroxine. Am J Med. 1987;82:1167-70. [PMID: 0003605133]

11. Diamond T, Nery L, Hales I. A therapeutic dilemma: suppressive doses of thyroxine significantly reduce bone mineral measurements in both premenopausal and postmenopausal women with thyroid carcinoma. J Clin Endocrinol Metab. 1991;72:1184-8. [PMID: 0002026740]

12. Greenspan SL, Greenspan FS, Resnick NM, Block JE, Friedlander AL, Genant HK. Skeletal integrity in premenopausal and postmenopausal women receiving long-term L-thyroxine therapy. Am J Med. 1991;91:5-14. [PMID: 0001858829]

13. Adlin EV, Maurer AH, Marks AD, Channick BJ. Bone mineral density in postmenopausal women treated with L-thyroxine. Am J Med. 1991;90:360-6. [PMID: 0002003518]

14. Gam AN, Jensen GF, Hasselstrom K, Olsen M, Nielsen KS. Effect of thyroxine therapy on bone metabolism in substituted hypothyroid patients with normal or suppressed levels of TSH. J Endocrinol Invest. 1991;14:451-5. [PMID: 0001774441]

15. Lehmke J, Bogner U, Felsenberg D, Peters H, Schleusener H. Determination of bone mineral density by quantitative computed tomography and single photon absorptiometry in subclinical hyperthyroidism: a risk of early osteopaenia in post-menopausal women. Clin Endocrinol (Oxf). 1992;36:511-7. [PMID: 0001617803]

16. Franklyn JA, Betteridge J, Daykin J, Holder R, Oates GD, Parle JV, et al. Long-term thyroxine treatment and bone mineral density. Lancet. 1992;340:913. [PMID: 0001351654]

17. Bauer D, Black D, Ashby M, Cummings S. Thyroid function and bone mass in older women. In: Christiansen C, ed. Proceedings from the Fourth International Symposium on Osteoporosis, Hong Kong, 27 March-2 April 1993. Hong Kong: Aalborg ApS; 1993:170-1.

18. Fraser SA, Anderson JB, Smith DA, Wilson GM. Osteoporosis and fractures following thyrotoxicosis. Lancet. 1971;1:981-3. [PMID: 0004102450]

19. Solomon BL, Wartofsky L, Burman KD. Prevalence of fractures in postmenopausal women with thyroid disease. Thyroid. 1993;3:17-23. [PMID: 0008499760]

20. Leese GP, Jung RT, Guthrie C, Waugh N, Browning MC. Morbidity in patients on L-thyroxine: a comparison of those with a normal TSH to those with a suppressed TSH. Clin Endocrinol (Oxf). 1992;37:500-3. [PMID: 0001286519]

21. Wejda B, Hintze G, Katschinski B, Olbricht T, Benker G. Hip fractures and the thyroid: a case-control study. J Intern Med. 1995;237:241-7. [PMID: 0007891045]

22. Wartofsky L. Levothyroxine therapy and osteoporosis. An end to the controversy? Arch Intern Med. 1995;155:1130-1. [PMID: 0007763118]

23. Franklyn JA, Daykin J, Betteridge J, Hughes EA, Holder R, Jones SR, et al. Thyroxine replacement therapy and circulating lipid concentrations. Clin Endocrinol (Oxf). 1993;38:453-9. [PMID: 0008330440]

24. Compston JE. Thyroid hormone therapy and the skeleton. Clin Endocrinol (Oxf). 1993;39:519-20. [PMID: 0008252738]

3 April $2001 \mid$ Annals of Internal Medicine $\mid$ Volume 134 • Number $7 \mid \mathbf{5 6 7}$ 
ARTICLE $\mid$ Low Serum Levels of Thyroid-Stimulating Hormone and Risk for Fracture

25. Baran DT. Thyroid hormone and bone mass: the clinician's dilemma [Editorial]. Thyroid. 1994;4:143-4. [PMID: 0007919994]

26. Ross DS. Hyperthyroidism, thyroid hormone therapy, and bone. Thyroid. 1994;4:319-26. [PMID: 0007833670]

27. Bauer DC, Browner WS, Cauley JA, Orwoll ES, Scott JC, Black DM, et al. Factors associated with appendicular bone mass in older women. The Study of Osteoporotic Fractures Research Group. Ann Intern Med. 1993;118:657-65. [PMID: 0008460853]

28. Genant HK, Jergas M, Palermo L, Nevitt M, Valentin RS, Black D, et al. Comparison of semiquantitative visual and quantitative morphometric assessment of prevalent and incident vertebral fractures in osteoporosis. The Study of Osteoporotic Fractures Research Group. J Bone Miner Res. 1996;11:984-96. [PMID: 0008797120]

29. Orwoll ES, Bauer DC, Vogt TM, Fox KM. Axial bone mass in older women. Study of Osteoporotic Fractures Research Group. Ann Intern Med. 1996;124:187-96. [PMID: 0008533993]

30. Spencer CA, Takeuchi M, Kazarosyan M. Current status and performance goals for serum thyrotropin (TSH) assays. Clin Chem. 1996;42:140-5. [PMID: 0008565217]

31. Stall GM, Harris S, Sokoll LJ, Dawson-Hughes B. Accelerated bone loss in hypothyroid patients overtreated with L-thyroxine. Ann Intern Med. 1990;113: 265-9. [PMID: 0002375563]

32. Kashiwai T, Ichihara K, Tamaki H, Endo Y, Kimura M, Takeoka K, et al. The stability of immunological and biological activity of human thyrotropin in buffer: its temperature-dependent dissociation into subunits during freezing. Scand J Clin Lab Invest. 1991;51:417-23. [PMID: 0001947726]

33. Spencer CA, Schwarzbein D, Guttler RB, LoPresti JS, Nicoloff JT. Thyrotropin (TSH)-releasing hormone stimulation test responses employing third and fourth generation TSH assays. J Clin Endocrinol Metab. 1993;76:494-8. [PMID: 0008432796]

34. Sawin CT, Geller A, Wolf PA, Belanger AJ, Baker E, Bacharach P, et al. Low serum thyrotropin concentrations as a risk factor for atrial fibrillation in older persons. N Engl J Med. 1994;331:1249-52. [PMID: 0007935681]

35. Nevitt MC, Ettinger B, Black DM, Stone K, Jamal SA, Ensrud K, et al. The association of radiographically detected vertebral fractures with back pain and function: a prospective study. Ann Intern Med. 1998;128:793-800. [PMID: 0009599190]

36. Black DM, Palermo L, Nevitt MC, Genant HK, Epstein R, San Valentin $\mathrm{R}$, et al. Comparison of methods for defining prevalent vertebral deformities: the Study of Osteoporotic Fractures. J Bone Miner Res. 1995;10:890-902. [PMID: 0007572313]

37. Kiel D. Assessing vertebral fractures. National Osteoporosis Foundation Working Group on Vertebral Fractures. J Bone Miner Res. 1995;10:518-23. [PMID: 0007610921]

38. Prentice RL. On the design of synthetic case-control studies. Biometrics. 1986;42:301-10. [PMID: 0003741972]
39. Barlow WE, Ichikawa L, Rosner D, Izumi S. Analysis of case-cohort designs. J Clin Epidemiol. 1999;52:1165-72. [PMID: 0010580779]

40. Cummings SR, Browner WS, Bauer D, Stone K, Ensrud K, Jamal S, et al. Endogenous hormones and the risk of hip and vertebral fractures among older women. Study of Osteoporotic Fractures Research Group. N Engl J Med. 1998; 339:733-8. [PMID: 0009731089]

41. Bayley TA, Harrison JE, McNeill KG, Mernagh JR. Effect of thyrotoxicosis and its treatment on bone mineral and muscle mass. J Clin Endocrinol Metab. 1980;50:916-22. [PMID: 0007372779]

42. Krolner B, Jorgensen JV, Nielsen SP. Spinal bone mineral content in myxoedema and thyrotoxicosis. Effects of thyroid hormone(s) and antithyroid treatment. Clin Endocrinol (Oxf). 1983;18:439-46. [PMID: 0006603290]

43. Lee MS, Kim SY, Lee MC, Cho BY, Lee HK, Koh CS, et al. Negative correlation between the change in bone mineral density and serum osteocalcin in patients with hyperthyroidism. J Clin Endocrinol Metab. 1990;70:766-70. [PMID: 0002307730]

44. Bauer DC, Nevitt MC, Ettinger B, Stone K. Low thyrotropin levels are not associated with bone loss in older women: a prospective study. J Clin Endocrinol Metab. 1997;82:2931-6. [PMID: 0009284722]

45. Ross DS, Ardisson LJ, Nussbaum SR, Meskell MJ. Serum osteocalcin in patients taking L-thyroxine who have subclinical hyperthyroidism. J Clin Endocrinol Metab. 1991;72:507-9. [PMID: 0001991818]

46. Garnero P, Hausherr E, Chapuy MC, Marcelli C, Grandjean H, Muller C, et al. Markers of bone resorption predict hip fracture in elderly women: the EPIDOS Prospective Study. J Bone Miner Res. 1996;11:1531-8. [PMID: 0008889854]

47. Cummings S, Black D, Ensrud K, Sklarin P, Arnaud C, Genant H. Urine markers of bone resorption predict hip bone loss and fractures in older women: the Study of Osteoporotic Fractures [Abstract]. J Bone Miner Res. 1996; 11(Suppl 1):S128.

48. Hallengren B, Elmstahl B, Berglund J, Christensen SB, Elmstahl S, Johnell $\mathrm{O}$, et al. No increase in fracture incidence in patients treated for thyrotoxicosis in Malmo during 1970-74. A 20-year population-based follow-up. J Intern Med. 1999;246:139-44. [PMID: 0010447782]

49. Seppel T, Becker A, Lippert F, Schlaghecke R. Serum sex hormone-binding globulin and osteocalcin in systemic nonthyroidal illness associated with low thyroid hormone concentrations. J Clin Endocrinol Metab. 1996;81:1663-5. [PMID: 0008636386]

50. Ross DS, Daniels GH, Gouveia D. The use and limitations of a chemiluminescent thyrotropin assay as a single thyroid function test in an outpatient endocrine clinic. J Clin Endocrinol Metab. 1990;71:764-9. [PMID: 0002394778]

51. Bayer MF. Effective laboratory evaluation of thyroid status. Med Clin North Am. 1991;75:1-26. [PMID: 0001987438]

52. Sawin CT. Subclinical hypothyroidism in older persons. Clin Geriatr Med. 1995;11:231-8. [PMID: 0007606692] 